OPEN ACCESS

Edited by:

Oliver Nicholas Shipley, The University of New Mexico, United States

Reviewed by:

Geraldine Busquets-Vass, The University of New Mexico,

United States

*Correspondence:

Jeremy J. Kiszka jkiszka@fiu.edu

Specialty section:

This article was submitted to Marine Megafauna,

a section of the journal

Frontiers in Marine Science

Received: 27 October 2021

Accepted: 27 January 2022

Published: 25 February 2022

Citation:

Kiszka JJ, Woodstock MS and Heithaus MR (2022) Functional Roles and Ecological Importance of Small Cetaceans in Aquatic Ecosystems. Front. Mar. Sci. 9:803173. doi: 10.3389/fmars.2022.803173

\section{Functional Roles and Ecological Importance of Small Cetaceans in Aquatic Ecosystems}

\author{
Jeremy J. Kiszka*, Matthew S. Woodstock and Michael R. Heithaus \\ Department of Biological Sciences, Institute of Environment, Florida International University, North Miami, FL, United States
}

Small cetaceans (dolphins, porpoises, and small toothed whales) occur from the poles to the tropics, and from freshwater habitats to the open ocean. Most ecological research has focused on the influence of abiotic factors on the abundance, distribution, and behavior of these species. The ecological impacts of small cetaceans on communities and ecosystems remain poorly quantified. Their movement patterns, often high local and regional abundances across a range of ecosystems, and high metabolic rates suggest that small cetaceans could have large effects on ecosystem structure, dynamics, and function through a variety of mechanisms. These include top-down (e.g., direct predation and risk effects) and bottom-up effects (e.g., translocation of nutrients within and across ecosystems), but also behavior-mediated processes where these predators can facilitate access to resources to other predators or modify the physical properties of habitat (e.g., bioturbation). Most small cetaceans can be consumed by other marine predators, particularly killer whales (Orcinus orca) and large sharks. Although consumption rates of small cetaceans can be high, there is a paucity of information on their effects on population sizes or behaviors of their prey. Mass-balance ecosystem models suggest that small cetaceans may impact the populations of short-lived prey species (particularly fish and cephalopods), but other factors (e.g., eutrophication and fisheries) also affect ecosystem functioning and population trends. Delphinids can also mediate the translocation and recycling of limiting nutrients between spatially distinct ecosystems on a diel basis. Despite intriguing possibilities, large gaps remain in our understanding of the roles and importance of small cetaceans in aquatic ecosystems, both marine and freshwater.

Keywords: Delphinidae, Phocoenidae, trophic interactions, predator-prey interactions, non-consumptive effects, ecosystem modeling, nutrient dynamics, bioturbation

\section{INTRODUCTION}

Understanding the ecological roles and importance of large-bodied aquatic consumers (particularly high trophic level predators) has been the focus of an increasing number of studies over the past two decades, including marine mammals, sharks, sea turtles, seabirds, and crocodilians (e.g., Katona and Whitehead, 1988; Bowen, 1997; Heithaus et al., 2008; Heithaus, 2013; Roman et al., 2014; Kiszka et al., 2015; Estes et al., 2016; Roff et al., 2016; Somaweera et al., 2020). While these studies and reviews have demonstrated that species within each of these taxa may play important roles, both as 
predators and prey, it is becoming increasingly apparent that there is a need to better understand the diversity of functional roles predators have in aquatic ecosystems, the pathways through which they might affect the structure and function of biological communities and ecosystems, and the contexts in which species may be more or less important. Such an understanding is critical because populations of large-bodied consumers are still in flux with many decreasing but others increasing or being targeted for population recovery (Nelms et al., 2021).

Dolphins (Platanistidae, Iniidae, Lipotidae ${ }^{1}$, Pontoporiidae, and Delphinidae), porpoises (Phocoenidae) and small toothed whales (Monodontidae and Kogiidae) are the smallest members of the odontocete suborder. They range across all latitudes, from the poles to the tropics, and occur from freshwater to open ocean ecosystems. They also exhibit a wide range of body sizes, from $150 \mathrm{~cm}$ and $48 \mathrm{~kg}$ for the vaquita (Phocoena sinus) to $980 \mathrm{~cm}$ and $10,000 \mathrm{~kg}$ for the killer whale (Orcinus orca). There are 51 extant species of small odontocetes (although assigning a species to this category remains slightly subjective) from seven families currently recognized by the Committee on Taxonomy of the Society for Marine Mammalogy ${ }^{2}$. These species occupy relatively a range of trophic levels in food webs, but the majority of species are mesopredators (Pauly et al., 1998). Small cetaceans can consume significant amounts of biomass due to the combined effects of high metabolic rates and high local/regional abundance, at least in some ecosystems. Their movements and diving abilities are extremely variable. The majority forage in shallow aquatic ecosystems (both freshwater and marine) or in epipelagic waters, but some species feed at depths up to and exceeding $1,000 \mathrm{~m}$ on mesopelagic prey (Spitz et al., 2006; Jensen et al., 2011).

To date, most studies on the ecology of small cetaceans have focused on describing their habitat preferences in relation to environmental parameters, primarily abiotic conditions (e.g., Parra, 2006; Cañadas and Hammond, 2008; Marubini et al., 2009), their movements across multiple spatial and temporal scales (Wells et al., 1999; Elwen et al., 2006; Durban and Pitman, 2012), and their trophic interactions (Spitz et al., 2006; Giménez et al., 2018; Kiszka et al., 2021). Therefore, most research efforts have focused on understanding the effects of marine ecosystems on these species (Estes et al., 2016). However, little research has been dedicated to understanding how these predators affect populations, communities, and ecosystems (Katona and Whitehead, 1988; Kiszka et al., 2015; Estes et al., 2016). Here, we review the diversity of roles small cetaceans can play in marine ecosystems, and investigate our current knowledge of their ecological importance.

\section{ROLES VS. IMPORTANCE}

There is often some confusion about the use of "ecological role/roles" and "ecological importance" (but see Heithaus et al., 2010; Kiszka et al., 2015). The ecological roles of a species include their position in the food web ("what it eats and what eats it";

\footnotetext{
${ }^{1}$ Functionally extinct.

${ }^{2}$ https://marinemammalscience.org/science-and-publications/list-marinemammal-species-subspecies
}

Heithaus et al., 2010), but also a multitude of other non-feeding interactions, including behavioral facilitation (whereby predators facilitate access to food resources to other predators), habitat modification (e.g., bioturbation), the translocation of nutrients within and across ecosystems, and potentially other behaviordriven roles (Kiszka et al., 2015). The ecological importance of species refers to the community and ecosystem consequences of changes in their abundance.

\section{DIRECT PREDATION EFFECTS}

The effects of direct predation by small cetaceans on their prey have received limited empirical attention (but see Williams et al., 2004, for example). Quantifying the importance of these effects remains a challenge in ecology, particularly in fluid marine ecosystems (Matassa and Trussell, 2011; Kindinger and Albins, 2017). Mass-balanced ecosystem-based models are a popular approach to assess the trophic regimes of marine ecosystems and the trophic role of organisms. Most small cetaceans consume low-mid trophic level fishes and cephalopods (Pauly et al., 1998), but others such as the killer or false killer whale (Pseudorca crassidens) consume other upper trophic level predators (large teleosts, other small cetaceans, sharks; Heithaus, 2001). The effects of predation, however, remain unclear except in a limited number of cases. Following a collapse of large whales in the North Pacific, killer whales are thought to have contributed to the decline of several species of smaller marine mammals, particularly pinnipeds (Eumetopias jubatus and Phoca vitulina) and sea otters (Enhydra lutris) through predation. Metabolic rate estimates indicate that one killer whale pod can consume 1,200 Steller sea lions per year and just 40 killer whales could have caused the observed collapse in the population, while just five killer whales are necessary to cause the decline of sea otters (Williams et al., 2004). In kelp forest ecosystems, the decline of sea otters has resulted in a trophic cascade, whereby sea urchin populations (sea otter main prey) have dramatically increased, leading to the decline of kelp forests due to overgrazing by sea urchins (Estes et al., 1998, 2004; Springer et al., 2003). However, although consumptive effects are thought to be the primary cause of the decline of sea otters and several pinniped species in the North Pacific, there is still a lack of knowledge on the relative importance of consumptive and risk effects on the dynamics and strength of these cascading effects (Estes et al., 2016).

Ecosystem-based models have been used to estimate the effects of the removal of predators, including small cetaceans, to help address gaps in empirical data. These models suggest that changing upper trophic level predator population sizes and diets result in changes in population sizes of species including beyond those with direct trophic linkages (Lassalle et al., 2012). In the 1970s, overexploitation-driven declines in dolphin populations, in concert with overfishing of commercial fishes, were associated with growth of non-commercial planktivorous fish populations, and declines in zooplankton populations (Daskalov, 2002). These changes resulted in reduced grazing pressure on phytoplankton communities, and eutrophication by the 1980s (Akoglu et al., 2014). However, the Black Sea was also experiencing greater 
riverine nutrient input, making it difficult to determine the importance of declines in small cetacean populations in driving these overall changes to the ecosystem relative to other stressors. The role of cetaceans as keystone functional groups (high impact and low biomass) has been repeatedly predicted from ecosystem models (Libralato et al., 2006; Valls et al., 2015), but ecosystem-based models may not solely be able to determine the consumptive effects of small cetaceans. The predictability of these models are constrained by limitations in our knowledge (e.g., food web topology and empirically derived population trends), and ecosystems are often complex and simultaneously affected by numerous factors (e.g., population size changes and anthropogenic stressors). The collection of holistic, multi-trophic level observational data, ideally in small ecosystems with limited interactions, may be the most appropriate way to identify the consumptive effects of cetaceans in marine ecosystems and would help refine ecosystem-based models. Indirect, ecosystemlevel impacts of cetacean consumptive effects require further empirical recognition. However, in relation to modeling, in situ data collection is more time consuming, costly, and potentially limited in spatial and temporal scope. The use of both methods is therefore necessary to determine the influence of cetaceanmediated consumptive effects amidst global declines in apex predator abundances.

\section{RISK EFFECTS}

Animals adopt behaviors (or suites of behaviors) to reduce the probability of being killed by predators (Lima and Dill, 1990). Investment in anti-predator tactics can be substantial and take multiple forms, from grouping to changes in habitat and resource use, even when predator-inflicted mortality is rare (Heithaus et al., 2008; Creel, 2011). Behavioral responses to risk are highly variable and depend on intrinsic characteristics of predator (foraging mode), prey (escape tactics) and context-dependent (physical features of habitats, such as depth and water visibility; see Wirsing et al., 2021). In addition, the physiological status (e.g., pregnancy and body condition) of individuals experiencing and mitigating risks can have major impacts on the energetic cost of prediction risk (Heithaus et al., 2008; Srinivasan et al., 2018). Overall, predation risk can result in losses of foraging and reproductive opportunities, and increased energetic costs due to investments to reduce the risk of being killed by a predator (Creel and Christianson, 2008).

The impacts of predation risk induced and experienced by small cetaceans have generally been overlooked. The perception of risk from predators can result in short- to long-term responses across multiple spatial and temporal scales. Immediate responses can include flight, freeze, mobbing or predator inspection, whereas long-term responses can induce shifts in habitat use, change in foraging behavior, and social cohesion (Kiszka et al., 2015; Srinivasan, 2019). For example, in the north-eastern Pacific, immediate risk from killer whales will induce coalescing movements from harbor (Phocoena phocoena) and Dall's porpoises (Phocoenides dalli) into shallow coastal waters (Jefferson et al., 1991). In pelagic waters, where diel vertical migrations occur, foraging delphinids induce behavioral responses to the diving behavior of mesopelagic organisms (Urmy and Benoit-Bird, 2021). Long-term responses most commonly involve habitat shifts. In Shark Bay, Western Australia, Indo-Pacific bottlenose dolphins (Tursiops aduncus) avoid productive seagrass habitats when tiger sharks (Galeocerdo cuvier) are more abundant, and favor safer deeper channels where prey is scarcer (Heithaus and Dill, 2002; Figure 1). Off Kaikoura, New Zealand, predation risk from killer whales can result in a $38 \%$ loss of foraging time for dusky dolphins due to the cost of commuting between offshore nighttime feeding grounds to safer inshore resting habitats used during daytime (Srinivasan et al., 2010). Similarly, spinner dolphins (Stenella longirostris) around tropical islands and atolls use shallow lagoons, bays, and shallow reef banks for resting and socializing after foraging offshore at night on mesopelagic prey, and this strategy seem to be driven by predation risk from large sharks and possibly large delphinids (Norris and Dohl, 1980; Heithaus, 2001; Kiszka et al., 2011). Several delphinid species are also known to form mixed-species groups to increase vigilance and dilute attack probabilities on individual group members in habitats where predation risk is perceived as high (see Syme et al., 2021, for a review). These "associations" can be initiated by one species and also result in a habitat shift, where one will move from its preferred habitat to the habitat preferentially used by another to associate with it.

Predation risk can also change through time to due to longterm changes in predator abundance and distribution. In the eastern Canadian Arctic, the increasing occurrence of killer whales due to the decline of sea ice has resulted in increasing predation pressure on arctic cetaceans, particularly narwhals (Monodon monoceros) but also bowhead whales (Balaena mysticetus) and beluga whales (Delphinapterus leucas; Ferguson et al., 2010). This is resulting in shifts in the spatial and temporal patterns of abundance of these species, which might eventually have consequences on the fitness of individuals and populations (Laidre et al., 2006; Breed et al., 2017). Because of the likely effects of climate change on predator and prey abundance and distribution, temporal shifts in predation risk should be incorporated into future studies of the ecological importance of small cetaceans.

Increasingly, it is being recognized that the effects of predation risk can cascade through food webs. Behavior-mediated indirect interactions (BMIIs) can occur as changes in the behavior of one species (or a segment of a given population, the transmitter) in response to another species (e.g., predator, the initiator) will in turn affect the behavior of a third group (the receiver; Dill et al., 2003). One of the most obvious examples of a BMII (sometimes referred to as a behavior-mediated trophic cascade) involving small cetaceans are when they (as initiators) drive schooling fish (transmitters) to the surface, making them more available to seabirds and other predators (receivers) (Dill et al., 2003; see below). A BMII may also occur where tiger sharks induce habitat shifts in dolphins that would result in reduced (high risk habitats) or increased (low risk habitats) predation rates and risk for small teleosts (Heithaus and Dill, 2002). The effects of these shifts by dolphins on teleost populations and behavior, however, are unquantified. 

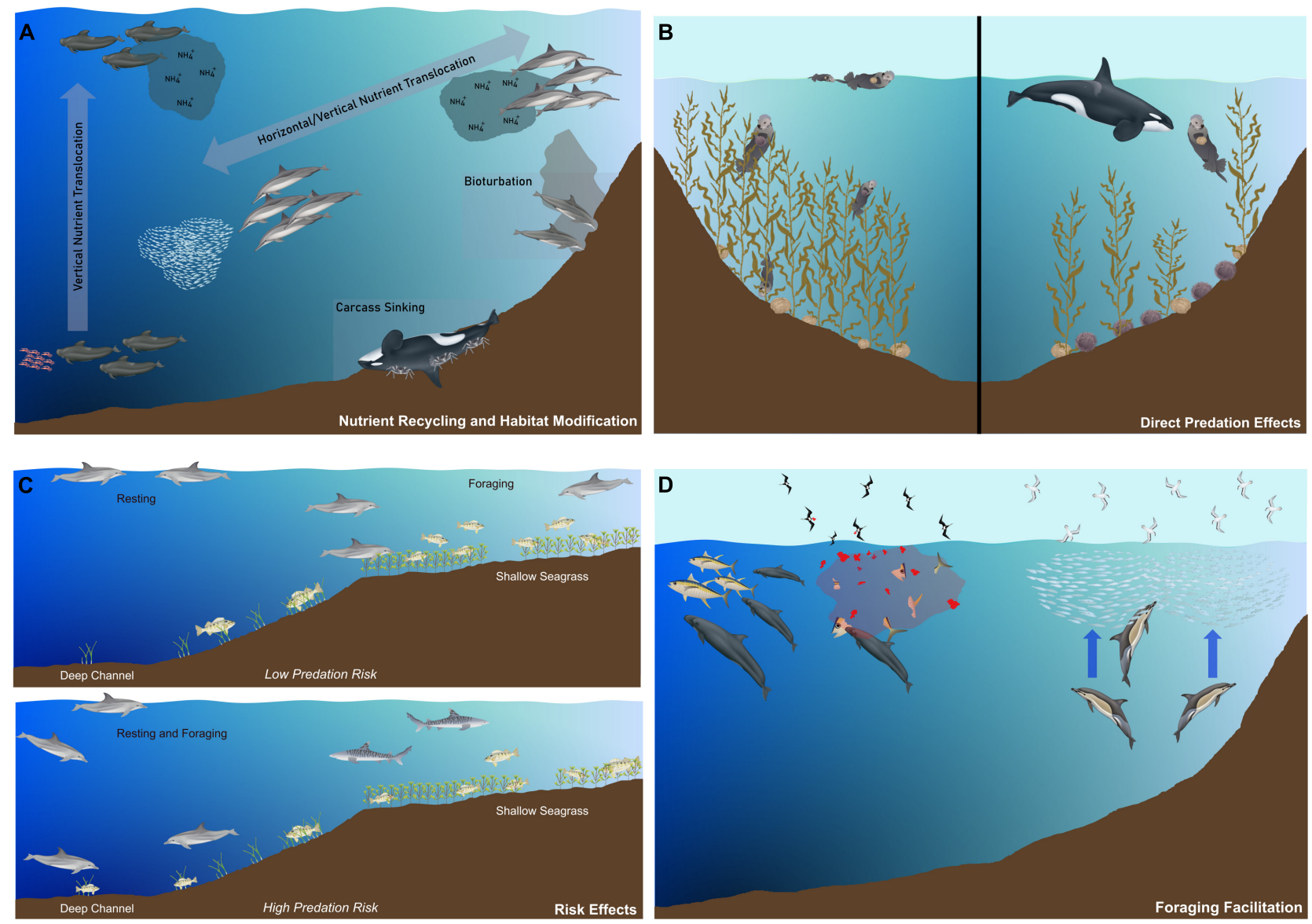

FIGURE 1 | Conceptual model of the ecological roles of small cetaceans in aquatic food webs (primarily marine). (A) Small cetaceans can mediate the translocation of limiting nutrients vertically (e.g., foraging on mesopelagic prey and sinking carcasses), horizontally (e.g., offshore foraging and resting/avoiding predators during the day in coastal waters), and through bioturbation. (B) Small cetaceans can mediate the consumptive effects of other predators in the ecosystem (e.g., killer whale, sea otter, sea urchin, kelp forests; Estes et al., 1998). (C) Small cetaceans may alter their foraging behavior and habitat utilization in response to the presence of predators (e.g., Shark Bay, Australia; Heithaus and Dill, 2002). (D) Small cetaceans influence the prey availability for other organisms in the ecosystem (e.g., Parkinson's petrels feeding on prey scraps (left; Pitman and Ballance, 1992) and small fishes forced closer to the surface by the fear of predation by small cetaceans, making the fishes available for seabird predation (right)].

\section{FORAGING FACILITATION}

Within marine predator communities, some species can facilitate the foraging of co-occurring predators by making previously unavailable prey accessible (Dill et al., 2003; Kiszka et al., 2015; Figure 1). Multiple (but scattered and often opportunistic) examples in the literature from diverse coastal and oceanic ecosystems suggest that several species of small cetaceans (primarily delphinids) facilitate foraging and enhance feeding rates of other surface-dwelling predators, particularly epipelagic sharks, seabirds, and possibly baleen whales (Balaenoptera sp.). In some cases, particularly in oligotrophic ecosystems, foraging facilitation could be critical for the survival of epipelagic seabirds, particularly Procellariformes (petrels). Thus, in the eastern tropical Pacific, Parkinson's petrels (Procellaria parkinsoni) associate with melon-headed whales (Peponocephala electra) or false killer whales (Pseudorca crassidens) to feed on prey scraps (Pitman and Ballance, 1992; Figure 1). If Parkinson's petrels exclusively rely on this source of food, the presence of cetaceans would be critical for their survival. The dynamics and contextdependence of foraging facilitation has not been investigated in detail, and further research is needed to assess its importance for many epipelagic predators, particularly seabirds.

\section{BIOTURBATION}

Foraging tactics adopted by marine consumers can affect the physical structure of habitats, a form of "ecosystem engineering" (Nelson et al., 1983; Nakaoka et al., 2002; Ray et al., 2006). Bioturbation is recognized as a major (but overlooked) driver of ecosystem dynamics and evolution (Meysman et al., 2006). A few species of small cetaceans potentially have an impact on benthic communities, particularly coastal delphinids feeding on benthic prey (Figure 1). For example, foraging bottlenose dolphins in the wider Caribbean region use tactics 
(e.g., mud-ring or mud-plume feeding) where they create sediment plumes to confuse their prey and increase foraging efficiency (Lewis and Schroeder, 2003; Torres and Read, 2009), which are visible from space (Ramos et al., 2021). In the Bahamas, crater feeding bottlenose dolphins dig in the benthos to find their prey (Rossbach and Herzing, 1997), and turn over considerable amounts of sand when doing so. However, the importance of bioturbation, particularly on infaunal communities, is unknown. Although bioturbation could have a negative effect on infaunal communities, it could promote nutrient dynamics by increasing microbial activity on the benthos, and contribute to increasing nitrogen fixation (Perry and Dennison, 1996). Benthic foraging is used by multiple species of small cetaceans (particularly common bottlenose dolphins) across many coastal ecosystems, but its impact on habitat modification, nutrient dynamics, and on infaunal communities needs to be further investigated.

\section{NUTRIENT CYCLING AND TROPHIC COUPLING}

Animal-mediated movements of nutrients within and across ecosystems can be significant, both in terrestrial and marine ecosystems (Doughty et al., 2016). Similar to large whales (Roman et al., 2014), small cetaceans release fecal plumes and urinate near the surface after feeding at depths, but can also contribute to water mixing when diving, particularly in well stratified waters (Dewar et al., 2006). While rates of nutrient transport remain unexplored for small cetaceans, there is a possibility that they could move ecologically relevant amounts of nutrients in several contexts. A diversity of small cetacean species feed in multiple habitats (e.g., upstream sections of estuaries, coastal seagrass meadows and pelagic waters on the continental shelf for T. truncatus, for example), or use distinct habitats that fulfill different functions (coastal or reef-associated resting grounds and offshore feeding grounds for Lagenorhynchus obscurus and Stenella longirostris, for example; Figure 1), and can therefore mediate the translocation and recycling of limiting nutrients. These horizontal movements can occur on a diel basis, and contribute to deposit nutrients from one habitat or ecosystem to another. Second, deep diving species (e.g., Fraser's dolphins Lagenodelphis hosei and spinner dolphins feeding on the deep scattering layer; Dolar et al., 2003) can translocate nutrient by foraging on mesopelagic prey, and excrete/defecate in surface waters during resting/traveling and between foraging dives (e.g., G. macrorhynchus and O. orca), which is similar to the "whale pump" process described for large whales (Roman et al., 2014; Figure 1). Even if small cetaceans forage and defecate in similar habitats, they could also play a major role in biogeochemical cycling processes through the consumption of nutrient-rich prey and subsequent egestion/excretion. To date, no studies have assessed small cetacean-mediated nutrient movements and recycling, although a range of species could significantly affect nutrient dynamics, particularly when small cetaceans mediate the translocation of nutrients from productive foraging to nutrient-poor habitats, and therefore link spatially distinct ecosystems.

\section{SUMMARY}

While there are increasing efforts to improve our understanding of the ecological roles and importance of small cetaceans, these efforts lag behind those focused on large whales (e.g., Roman et al., 2014; Doughty et al., 2016). With their high abundance in some ecosystems and widespread distribution, small cetaceans could have significant impact on the structure and function of aquatic ecosystems. These effects may be particularly important in tropical and warm temperate ecosystems that are oligotrophic or where interactions are spatially confined (e.g., small oceanic islands and riverine systems) and there may be limited dilution of their ecological impacts. These latter systems represent an important opportunity for quantifying effects of small cetaceans because they would theoretically be easier to detect and measure. Efforts to elucidate the ecological importance of small cetaceans, however, need to be focused largely on the behavior and population dynamics of their prey which remain poorly understood in many systems. A variety of possible roles that small cetaceans could play in marine ecosystems have not been investigated. For example, dolphin carcasses that strand and sink in deep waters have the potential to support numerous species (cf. whale falls; see Roman et al., 2014, for a review).

Understanding the ecological impacts of small cetaceans, whether large or relatively small, is important in light of the decline of an increasing number of species, mostly due to bycatch (Brownell et al., 2019). Today, 13 species, subspecies or populations of small cetaceans are classified as Critically Endangered on the IUCN Red List of Threatened Species. A major limit to assessing the ecological influences of small cetaceans is the difficulty to study these organisms (particularly their movements and feeding ecology) and their ecosystems. Despite the increasing availability of research tools and methods that are critical to understand the ecological roles of these predators, major gaps hinder our capability to properly measure a number of key attributes of their function, particularly their fine-scale movements, feeding rates, and prey selection. The development of biologging tools (e.g., animal-borne video and environmental data collection systems, AVEDs) or improving our understanding of uncertainty of mass-balance ecosystem models are one of many key elements to assessing the roles and function of small cetaceans (and other large marine consumers) in aquatic ecosystems.

\section{AUTHOR CONTRIBUTIONS}

JK led the writing of the review, with significant contributions from all other authors. All authors contributed to the article and approved the submitted version.

\section{ACKNOWLEDGMENTS}

We thank the reviewers for their comments and valuable inputs on the first version of the manuscript. We also thank Uko Gorter for allowing the use of his illustrations (delphinids) in Figure 1. This is contribution \#1409 from the Coastlines and Oceans Division of the Institute of Environment at Florida International University. 


\section{REFERENCES}

Akoglu, E., Salihoglu, B., Libralato, S., Oguz, T., and Solidoro, C. (2014). An indicator-based evaluation of Black Sea food web dynamics during 1960-2000. J. Mar. Syst. 134, 113-125. doi: 10.1016/j.jmarsys.2014.02.010

Bowen, W. (1997). Role of marine mammals in aquatic ecosystems. Mar. Ecol. Prog. Ser. 158, 267-274. doi: 10.3354/meps 158267

Breed, G. A., Matthews, C. J. D., Marcoux, M., Higdon, J. W., Le Blanc, B., Petersen, S. D., et al. (2017). Sustained disruption of narwhal habitat use and behavior in the presence of Arctic killer whales. Proc. Natl. Acad. Sci. U.S.A. 114, 2628-2633. doi: 10.1073/pnas.1611707114

Brownell, R. L., Reeves, R. R., Read, A. J., Smith, B. D., Thomas, P. O., Ralls, K., et al. (2019). Bycatch in gillnet fisheries threatens critically endangered small cetaceans and other aquatic megafauna. Endanger. Species Res. 40, 285-296. doi: 10.3354/ESR00994

Cañadas, A., and Hammond, P. S. (2008). Abundance and habitat preferences of the short-beaked common dolphin Delphinus delphis in the southwestern Mediterranean: implications for conservation. Endanger. Species Res. 4, 309331. doi: 10.3354/esr00073

Creel, S. (2011). Toward a predictive theory of risk effects: hypotheses for prey attributes and compensatory mortality. Ecology 92, 2190-2195. doi: 10.1890/ $11-0327.1$

Creel, S., and Christianson, D. (2008). Relationships between direct predation and risk effects. Trends Ecol. Evol. 23, 194-201. doi: 10.1016/j.tree.2007. 12.004

Daskalov, G. M. (2002). Overfishing drives a trophic cascade in the Black Sea. Mar. Ecol. Prog. Ser. 225, 53-63. doi: 10.3354/meps225053

Dewar, W. K., Bingham, R. J., Iverson, R. L., Nowacek, D. P., St. Laurent, L. C., and Wiebe, P. H. (2006). Does the marine biosphere mix the ocean? J. Mar. Res. 64, 541-561. doi: 10.1357/002224006778715720

Dill, L. M., Heithaus, M. R., and Walters, C. J. (2003). Behaviorally mediated indirect interactions in marine communities and their conservation implications. Ecology 84, 1151-1157.

Dolar, M. L. L., Walker, W. A., Kooyman, G. L., and Perrin, W. F. (2003) Comparative feeding ecology of spinner dolphins (Stenella longirostris) and Fraser's dolphins (Lagenodelphis hosei) in the Sulu Sea. Mar. Mammal Sci. 19, 1-19. doi: 10.1111/j.1748-7692.2003.tb01089.x

Doughty, C. E., Roman, J., Faurby, S., Wolf, A., Haque, A., Bakker, E., et al. (2016). Global nutrient transport in a world of giants. Proc. Natl. Acad. Sci. U.S.A. 113, 868-873. doi: 10.1073/pnas.1502549112

Durban, J. W., and Pitman, R. L. (2012). Antarctic killer whales make rapid, roundtrip movements to subtropical waters: evidence for physiological maintenance migrations? Biol. Lett. 8, 274-277. doi: 10.1098/rsbl.2011.0875

Elwen, S., Meÿer, M. A., Best, P. B., Kotze, P. G. H., Thornton, M., and Swanson, S. (2006). Range and movements of female heaviside's dolphins (Cephalorhynchus heavisidii), as determined by satellite-linked telemetry. J. Mammal. 87, 866-877. doi: 10.1644/05-MAMM-A-307R2.1

Estes, J. A., Danner, E. M., Doak, D. F., Konar, B., Springer, A. M., Steinberg, P. D., et al. (2004). Complex trophic interactions in kelp forest ecosystems. Bull. Mar. Sci. 74, 621-638

Estes, J. A., Heithaus, M., McCauley, D. J., Rasher, D. B., and Worm, B. (2016). Megafaunal impacts on structure and function of ocean ecosystems. Annu. Rev. Environ. Resour. 41, 83-116. doi: 10.1146/annurev-environ110615-085622

Estes, J. A., Tinker, M. T., Williams, T. M., and Doak, D. F. (1998). Killer Whale predation on sea otters linking oceanic and nearshore ecosystems. Science 282, 473-476. doi: 10.1126/science.282.5388.473

Ferguson, S. H., Loseto, L. L., and Mallory, M. L. (2010). A little less arctic: Top predators in the world's largest northern inland sea, hudson bay. Netherlands: Springer.

Giménez, J., Marçalo, A., García-Polo, M., García-Barón, I., Castillo, J. J., Fernández-Maldonado, C., et al. (2018). Feeding ecology of Mediterranean common dolphins: the importance of mesopelagic fish in the diet of an endangered subpopulation. Mar. Mammal Sci. 34, 136-154. doi: 10.1111/mms. 12442

Heithaus, M. R. (2001). Predator-prey and competitive interactions between sharks (order Selachii) and dolphins (suborder Odontoceti): a review. J. Zool. 253, 53-68. doi: 10.1017/S0952836901000061
Heithaus, M. R. (2013). "Predators, Prey, and the Ecological Roles of Sea Turtles,", in The Biology of Sea Turtles, Volume III, eds J. Wyneken, K. J. Lohmann, and J. A. Musick (Florida: CRC Press).

Heithaus, M. R., and Dill, L. M. (2002). Food availability and tiger shark predation risk influence bottlenose dolphin habitat use. Ecology 83, 480-491. doi: 10.1890/ 0012-9658(2002)083[0480:faatsp]2.0.co;2

Heithaus, M. R., Frid, A., Vaudo, J. J., Worm, B., and Wirsing, A. J. (2010). "Unraveling the ecological importance of elasmobranchs", in Sharks and their relatives $I I$, eds J. C. Carrier, J. A. Musick, and M. R. Heithaus (Florida: CRC Press), 627-654.

Heithaus, M. R., Frid, A., Wirsing, A. J., and Worm, B. (2008). Predicting ecological consequences of marine top predator declines. Trends Ecol. Evol. 23, 202-210. doi: 10.1016/j.tree.2008.01.003

Jefferson, T. A., Stacey, P. J., and Baird, R. W. (1991). A review of Killer Whale interactions with other marine mammals: predation to co-existence. Mamm. Rev. 21, 151-180. doi: 10.1111/j.1365-2907.1991.tb00291.x

Jensen, F. H., Perez, J. M., Johnson, M., Soto, N. A., and Madsen, P. T. (2011). Calling under pressure: short-finned pilot whales make social calls during deep foraging dives. Proc. R. Soc. B Biol. Sci. 278, 3017-3025. doi: 10.1098/rspb.2010. 2604

Katona, S., and Whitehead, H. (1988). Are cetacea ecologically important? Oceanogr. Mar. Biol. Annu. Rev. 26, 553-568.

Kindinger, T. L., and Albins, M. A. (2017). Consumptive and non-consumptive effects of an invasive marine predator on native coral-reef herbivores. Biol. Invasions, 19, 131-146. doi: 10.1007/s10530-016-1268-1

Kiszka, J., Heithaus, M., and Wirsing, A. (2015). Behavioural drivers of the ecological roles and importance of marine mammals. Mar. Ecol. Prog. Ser. 523, 267-281. doi: 10.3354/meps11180

Kiszka, J., Perrin, W. F., Pusineri, C., and Ridoux, V. (2011). What drives island-associated tropical dolphins to form mixed-species associations in the southwest Indian Ocean? J. Mammal. 92, 1105-1111. doi: 10.1644/10-MAMMA-376.1

Kiszka, J. J., Caputo, M., Méndez-Fernandez, P., and Fielding, R. (2021). Feeding ecology of elusive caribbean Killer Whales inferred from bayesian stable isotope mixing models and whalers' ecological knowledge. Front. Mar. Sci. 8:648421. doi: $10.3389 /$ fmars.2021.648421

Laidre, K. L., Heide-Jørgensen, M. P., and Orr, J. R. (2006). Reactions of Narwhals, Monodon monoceros, to Killer Whale, Orcinus orca, attacks in the eastern Canadian Arctic. Can. Field Nat. 120, 457-465. doi: 10.22621/cfn.v120i4.355

Lassalle, G., Gascuel, D., Loc'h, F. L., Lobry, J., Pierce, G. J., Ridoux, V., et al. (2012). An ecosystem approach for the assessment of fisheries impacts on marine top predators: the Bay of Biscay case study. ICES J. Mar. Sci. 69, 925-938. doi: $10.1038 / 278097 \mathrm{a} 0$

Lewis, J. S., and Schroeder, W. W. (2003). ). Mud Plume Feeding, A Unique Foraging Behavior of the Bottlenose Dolphin in the Florida Keys. Gulf Mex. Sci. 21, 92-97. doi: 10.18785/goms.2101.09

Libralato, S., Christensen, V., and Pauly, D. (2006). A method for identifying keystone species in food web models. Ecol. Modell. 195, 153-171. doi: 10.1016/ j.ecolmodel.2005.11.029

Lima, S. L., and Dill, L. M. (1990). Behavioral decisions made under the risk of predation: a review and prospectus. Can. J. Zool. 68, 619-640. doi: 10.1139/z90092

Marubini, F., Gimona, A., Evans, P. G. H., Wright, P. J., and Pierce, G. J. (2009). Habitat preferences and interannual variability in occurrence of the Harbour Porpoise Phocoena phocoena off northwest Scotland. Mar. Ecol. Prog. Ser. 381, 297-310. doi: 10.3354/meps07893

Matassa, C. M., and Trussell, G. C. (2011). Landscape of fear influences the relative importance of consumptive and nonconsumptive predator effects. Ecology 92, 2258-2266. doi: 10.1890/11-0424.1

Meysman, F. J. R., Middelburg, J. J., and Heip, C. H. R. (2006). Bioturbation: a fresh look at Darwin's last idea. Trends Ecol. Evol. 21, 688-695. doi: 10.1016/j. tree.2006.08.002

Nakaoka, M., Mukai, H., and Chunhabundit, S. (2002). Impacts of dugong foraging on benthic animal communities in a Thailand seagrass bed. Ecol. Res. 17, 625-638. doi: 10.1046/j.1440-1703.2002.00520.x

Nelms, S. E., Alfaro-Shigueto, J., Arnould, J. P. Y., Avila, I. C., Nash, S. B., Campbell, E., et al. (2021). Marine mammal conservation: over the horizon. Endanger. Species Res. 44, 291-325. doi: 10.3354/ESR01115 
Nelson, C. H., Johnson, K. R., and Barber, J. H. (1983). Assessment of Gray Whale Feeding Grounds and Sea Floor Interaction in the Northeastern Bering Sea. Virginia: US Geological Survey.

Norris, K. S., and Dohl, T. P. (1980). The behavior of Hawaiian spinner dolphin, Stenella longirostris. Fish. Bull. 77, 821-849.

Parra, G. J. (2006). Resource partitioning in sympatric delphinids: space use and habitat preferences of Australian snubfin and Indo-Pacific humpback dolphins. J. Anim. Ecol. 75, 862-874. doi: 10.1111/j.1365-2656.2006. 01104.x

Pauly, D., Trites, A. W., Capuli, E., and Christensen, V. (1998). Diet composition and trophic level of marine mammals. ICES J. Mar. Sci. 55, 467-481. doi: 10.1006/jmsc.1997.0280

Perry, C. J., and Dennison, W. C. (1996). "Effects of Dugong Grazing on Microbial Processes in Seagrass Sediments," in Seagrass biology: Proceedings of an international workshop, (Netherlands: University of Western Australia Faculty of Science).

Pitman, R. L., and Ballance, L. T. (1992). Parkinson's petrel distribution and foraging ecology in the eastern Pacific: aspects of an exclusive feeding relationship with dolphins. Condor 94, 825-835. doi: 10.2307/1369280

Ramos, E. A., Santoya, L., Verde, J., Walker, Z., Castelblanco-Martínez, N., Kiszka, J. J., et al. (2021). Lords of the Rings: mud ring feeding by bottlenose dolphins in a Caribbean estuary revealed from sea, air, and space. Mar. Mammal Sci. 38, 364-373. doi: $10.1111 / \mathrm{mms} .12854$

Ray, G. C., McCormick-Ray, J., Berg, P., and Epstein, H. E. (2006). Pacific walrus: benthic bioturbator of Beringia. J. Exp. Mar. Bio. Ecol. 330, 403-419. doi: 10. 1016/j.jembe.2005.12.043

Roff, G., Doropoulos, C., Rogers, A., Bozec, Y. M., Krueck, N. C., Aurellado, E., et al. (2016). The ecological role of sharks on coral reefs. Trends Ecol. Evol. 31, 395-407. doi: 10.1016/j.tree.2016.02.014

Roman, J., Estes, J. A., Morissette, L., Smith, C., Costa, D., McCarthy, J., et al. (2014). Whales as marine ecosystem engineers. Front. Ecol. Environ. 12:377385. doi: $10.1890 / 130220$

Rossbach, K. A., and Herzing, D. L. (1997). Underwater observations of benthicfeeding bottlenose dolphins (Tursiops truncatus). Mar. Mammal Sci. 13, 498504. doi: 10.1111/j.1748-7692.1997.tb00658.x

Somaweera, R., Nifong, J., Rosenblatt, A., Brien, M. L., Combrink, X., Elsey, R. M., et al. (2020). The ecological importance of crocodilians: towards evidence-based justification for their conservation. Biol. Rev. 95, 936-959. doi: 10.1111/brv. 12594

Spitz, J., Richard, E., Meynier, L., Pusineri, C., and Ridoux, V. (2006). Dietary plasticity of the oceanic striped dolphin, Stenella coeruleoalba, in the neritic waters of the Bay of Biscay. J. Sea Res. 55, 309-320. doi: 10.1016/j.seares.2006. 02.001

Springer, A. M., Estes, J. A., Van Vliet, G. B., Williams, T. M., Doak, D. F., Danner, E. M., et al. (2003). Sequential megafaunal collapse in the North Pacific Ocean: an ongoing legacy of industrial whaling? Proc. Natl. Acad. Sci. U.S.A. 100, 12223-12228. doi: $10.1073 /$ pnas. 1635156100
Srinivasan, M. (2019). "Predator/Prey Decisions and the Ecology of Fear," in Ethology and Behavioral Ecology of Odontocetes, ed. B. Würsig (New York, NY: Springer), 145-163.

Srinivasan, M., Grant, W. E., Swannack, T. M., and Rajan, J. (2010). Behavioral games involving a clever prey avoiding a clever predator: an individual-based model of dusky dolphins and killer whales. Ecol. Modell. 221, 2687-2698. doi: 10.1016/j.ecolmodel.2010.07.010

Srinivasan, M., Swannack, T. M., Grant, W. E., Rajan, J., and Würsig, B. (2018). To feed or not to feed? Bioenergetic impacts of fear-driven behaviors in lactating dolphins. Ecol. Evol. 8, 1384-1398. doi: 10.1002/ece3.3732

Syme, J., Kiszka, J. J., and Parra, G. J. (2021). Dynamics of cetacean mixed-species groups: a review and conceptual framework for assessing their functional significance. Front. Mar. Sci. 8:678173. doi: 10.3389/fmars.2021.678173

Torres, L. G., and Read, A. J. (2009). Where to catch a fish? the influence of foraging tactics on the ecology of bottlenose dolphins (Tursiops truncatus) in Florida Bay. Florida. Mar. Mammal Sci. 25, 797-815. doi: 10.1111/j.1748-7692.2009.00297.x

Urmy, S. S., and Benoit-Bird, K. J. (2021). Fear dynamically structures the ocean's pelagic zone. Curr. Biol. 31, 5086-5092.e3. doi: 10.1016/j.cub.2021.09.003

Valls, A., Coll, M., Christensen, V., and Ellison, A. M. (2015). Keystone species: toward an operational concept for marine biodiversity conservation. Ecol. Monogr. 85, 29-47. doi: 10.1890/14-0306.1

Wells, R. S., Rhinehart, H. L., Cunningham, P., Whaley, J., Baran, M., Koberna, C., et al. (1999). Long distance offshore movements of bottlenose dolphins. Mar. Mammal Sci. 15, 1098-1114.

Williams, T. M., Estes, J. A., Doak, D. F., and Springer, A. M. (2004). Killer appetites: assessing the role of predators in ecological communities. Ecology 85, 3373-3384. doi: 10.1890/03-0696

Wirsing, A. J., Heithaus, M. R., Brown, J. S., Kotler, B. P., and Schmitz, O. J. (2021). The context dependence of non-consumptive predator effects. Ecol. Lett. 24, 113-129. doi: 10.1111/ele.13614

Conflict of Interest: The authors declare that the research was conducted in the absence of any commercial or financial relationships that could be construed as a potential conflict of interest.

Publisher's Note: All claims expressed in this article are solely those of the authors and do not necessarily represent those of their affiliated organizations, or those of the publisher, the editors and the reviewers. Any product that may be evaluated in this article, or claim that may be made by its manufacturer, is not guaranteed or endorsed by the publisher.

Copyright (อ 2022 Kiszka, Woodstock and Heithaus. This is an open-access article distributed under the terms of the Creative Commons Attribution License (CC BY). The use, distribution or reproduction in other forums is permitted, provided the original author(s) and the copyright owner(s) are credited and that the original publication in this journal is cited, in accordance with accepted academic practice. No use, distribution or reproduction is permitted which does not comply with these terms. 